\title{
A EXPOSIÇÃO MACHADO DE ASSIS
}

Artigo originalmente publicado em $O$ Estado de S. Paulo, suplemento, $1^{\mathrm{a}}$ quinzena de agosto de 1939.

\section{MÁRIO DE ANDRADE}

\author{
APRESENTAÇÃO DE MARCELO DIEGO \\ Universidade Federal do Rio de Janeiro \\ Rio de Janeiro, Rio de Janeiro, Brasil
}

Resumo: Em agosto de 1939, Mário de Andrade publicou em O Estado de S. Paulo um artigo sobre a exposição comemorativa do centenário de nascimento de Machado de Assis, organizada pelo Instituto Nacional do Livro, que teve lugar na Biblioteca Nacional. No artigo, ele descreve a exposição, comenta o lugar privilegiado de Machado de Assis no quadro da literatura brasileira, discute o papel do intelectual, a importância da vida literária, a função das instituições culturais e o percurso formativo e de consagração da figura do escritor.

Palavras-chave: Exposição Machado de Assis; Instituto Nacional do Livro; Biblioteca Nacional; O Estado de S. Paulo.

\section{THE EXHIBITION MACHADO DE ASSIS}

Abstract: In August 1939, Mário de Andrade wrote an article for O Estado de S. Paulo about the exhibition in celebration of the centennial of Machado de Assis's birth organized by the National Book Institute and held at the National Library. In the article, Andrade describes the exhibition, comments on the privileged place of Machado de Assis in Brazilian literature, discusses the role of the intellectual, the importance of literary life, the function of cultural institutions and the path for forming and consecrating the figure of the writer.

Keywords: Machado de Assis Exhibition; National Book Institute; National Library; O Estado de S. Paulo. 
Mário de Andrade (São Paulo, 1893-1945) certamente dedicou-se à leitura de Machado de Assis durante os seus anos de formação, porém parece ter sido apenas na maturidade, e motivado principalmente por circunstâncias externas, que se dedicou à análise refletida sobre a obra do Bruxo do Cosme Velho. Em 1938, diante de uma série de dificuldades no Departamento Municipal de Cultura de São Paulo, que fundara em 1935 e então chefiava, aceitou o convite para assumir a cátedra de História da Arte na Universidade do Brasil, atual Universidade Federal do Rio de Janeiro, mudando-se para esta cidade e nela permanecendo até 1941, naquilo que veio a ser conhecido como o período do seu "exílio no Rio" (CASTRO, 1988). De seu apartamento na rua da Glória, esquina com rua Santo Amaro, colaborou regularmente com a imprensa carioca - de modo exemplar, na coluna "Vida Literária", do Diário de Notícias -, embora sem jamais se ausentar da imprensa de São Paulo e de todo o país - como prova o texto aqui apresentado, originalmente publicado no suplemento de $O$ Estado de $S$. Paulo. No Rio, Mário de Andrade pôde assistir, em primeira mão e de camarote, às celebrações do centenário de nascimento de Machado de Assis, em 1939, que tiveram como epicentro a capital federal.

Recentemente, Hélio de Seixas Guimarães e Ieda Lebensztayn, em Escritor por escritor - Machado de Assis segundo seus pares (1908-1939), recensearam a presença do escritor fluminense na vasta obra crítica e ensaística do autor paulista, presença que se concentra nos anos de 1938 a 1940, coincidindo, portanto, com a estada de Mário de Andrade no Rio de Janeiro e com as comemorações pelo centenário machadiano. Os textos elencados pelos dois pesquisadores são, em ordem cronológica: "Contos e contistas", em novembro de 1938; carta a Maurício Loureiro Gama, em junho de 1939; "Machado de Assis - I", "Última jornada - II" e "Machado de Assis III", nesse mesmo mês; "A Exposição Machado de Assis", em agosto de 1939; "A psicologia em ação", em novembro de 1939; "Os machadianos", em dezembro de 1939; e "Noticiário", em maio de 1940. Para a alegria (ou melhor, para a comodidade) do leitor contemporâneo, todos esses textos - à exceção de um - foram recolhidos em antologias póstumas, que podem ser encontradas com facilidade em bibliotecas, não se fazendo mais obrigatório o recurso ao original publicado na imprensa: "Contos e contistas" e "A psicologia em ação" estão em O empalhador de passarinho (ANDRADE, 1955); a carta a Maurício Loureiro Gama consta em um número da Revista do Instituto de Estudos Brasileiros e no volume organizado por Guimarães e Lebensztayn (2019); "Machado de Assis - I", "Última jornada - II" e 
"Machado de Assis - III", unificadas sob o título "Machado de Assis", fazem parte de Aspectos da literatura brasileira (ANDRADE, 1943); e "Os machadianos" e "Noticiário" integram Vida literária (ANDRADE, 1993). Único texto desse conjunto temático que ainda não havia sido transportado para espaço menos precário que o das páginas da imprensa diária, "A Exposição Machado de Assis" é reproduzido, agora, como ensaio "Da tradição crítica" da Machado de Assis em linha: revista eletrônica de estudos machadianos.

Se nos demais textos o autor de Macunaíma posiciona-se claramente como crítico, comentando quer a obra do criador de Brás Cubas (é o caso de "Contos e contistas", da carta a Maurício Loureiro Gama, de "Machado de Assis - I", "Última jornada - II", "Machado de Assis - III" e de "A psicologia em ação"), quer a sua recepção (como em "Os machadianos" e "Noticiário"), em "A Exposição Machado de Assis" ele parece fazer as vezes de repórter, adotando um registro eminentemente descritivo. Mário de Andrade pega o seu leitor pelo braço e o leva para uma visita à exposição, percorrendo seus espaços um a um, discorrendo sobre a sua organização e os seus organizadores, sobre os itens que ela exibe, suas escolhas e seus êxitos. Nesse sentido, trata-se de um importante testemunho de um evento em certa medida inaugural, no cenário brasileiro, no que diz respeito à preservação da memória e às práticas museológicas e curatoriais (e de que é documento o seu próprio Catálogo [MINISTÉRIO DA EDUCAÇÃO E SAÚDE PÚBLICA, 1939], publicado naquele mesmo ano). Contudo, sob o espelho d'água calmo da reportagem, agitam-se visões nada pacificadas sobre quais sejam o lugar de Machado de Assis no quadro da literatura nacional, o papel do intelectual, a função das instituições culturais e até mesmo a formação e a trajetória de todo aquele que se dedica à escrita. Assim, é possível também ouvir, no que Mário diz sobre Machado, ecos de questões que ele coloca para si mesmo e sobre si mesmo, em uma espécie de acerto de contas com uma figura da qual sempre procurou se afastar, mas da qual mais e mais se aproxima.

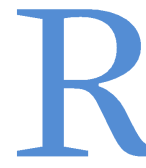

ealmente, o centenário de Machado de Assis deu lugar a uma das mais significativas manifestações de coesão nacional de que se tem notícia. Ninguém poderia supor, no início do ano, que a figura do 
genial criador do Brás Cubas comovesse tanto a alma nacional, mas a intelectualidade toda do país cerrou fileiras em torno do morto. $\mathrm{E}$ o mais admirável, o que demonstra realmente que a inteligência brasileira está em profundo adiantamento cultural e social, é que as manifestações quase todas, com exceção evidentemente das acadêmicas e de algumas oficiais, nada têm de apologéticas e patrioteiramente servis. É um culto esclarecido, em que o carinho, a atenção ambiciosa em torno de qualquer gesto ou obra de Machado de Assis não exclui a clarividência de julgamento, as censuras a certas atitudes sociais ou filosóficas do grande humorista e restrições à obra dele.

A própria Exposição Machado de Assis, organizada oficialmente sob a direção do jovem Instituto Nacional do Livro, com a colaboração da Biblioteca Nacional, que lhe emprestou local e documentos, é uma exposição de caráter crítico, o que pela primeira vez se faz no Brasil. Aliás, sob vários pontos de vista, ela é uma novidade entre nós. Planejada conjuntamente por Augusto Meyer, um dos mais argutos críticos de Machado de Assis, e pelo arquiteto Oscar Niemeyer, ela é de uma nobre expressão. A beleza das cores dos painéis e sua sóbria decoração, a escolha dos documentos mais característicos e raros, a sugestividade das suas divisões e das fotografias apresentadas, a comodidade do olhar e da compreensão imediata, bem como a transformação quase miraculosa de um recinto imprestável, tornam esta exposição uma réussite completa.

Convertido o saguão da Biblioteca mais ou menos num recinto circular, este se divide em gomos, cada qual correspondendo a uma seção do conjunto. Estas seções se referem à "Infância" de Machado de Assis, à sua "Formação", "Vida íntima", "Maturidade", "Crepúsculo", "Consagração" e "Obra". Na parte da infância, vemos o registo de batismo, o croqui da Chácara do Livramento com o desenho da capela em que o escritor foi batizado, além de várias fotografias desse morro do Livramento, que o próprio clássico evocou, muito mais tarde, na sua frase: "caçar ninhos de pássaros ou perseguir lagartixas nos morros do Livramento e da Conceição, ou simplesmente arruar à toa". Este painel é reproduzido aqui por uma das fotografias. Ainda mais feliz e evocativo é o painel seguinte, "Formação", também reproduzido numa das fotografias deste suplemento. É o período em que o mestre se ensaia nas letras. Além da documentação original, contida na mesa vidrada, vemos na parede as reproduções ampliadas dos primeiros amigos e mentores do escritor, Paula Brito, Manuel Antônio de Almeida, José de Alencar, Francisco Otaviano, [Quintino] Bocaiuva, Faustino Xavier 
de Novais, a quem ele dedicaria um dos seus poemas mais admiráveis, além dos jornais em que colaborou no tempo, em especial a Marmota Fluminense. Quanto à "Vida íntima", quase nada. O gênio que detestava os derramados nos deixou muito pouco do que foi no lar. Ele mesmo afirmava que "a descrição da vida não vale a sensação da vida". Um belo retrato de Carolina, no tempo em que se casou com o poeta, em 1869, outro do Machado de Assis dessa mesma época, e, numa redoma, o seu tinteiro, a caneta, o pince-nez. Chegamos então à maturidade. Uma vista do Ministério da Viação de que ele foi funcionário até morrer, uma admirável evocação da Academia que ele fundou e de que se tornou o protótipo (nas coisas boas...). O fac-símile da primeira página das Memórias póstumas de Brás Cubas e frontispícios de jornais em que colaborou então, A Gazeta de Notícias, A Estação. No "Crepúsculo", vemos Machado de Assis cultuado em vida e feliz. Um delicioso retrato de Carolina já grisalha, outro do clássico, o ramo do carvalho de Tasso, e a horrível máscara mortuária que nos enche de pavor. Qualquer coisa de um mico inchado que se risse. Um derradeiro traço de humorismo. Mas este foi a morte quem fez... Na "Consagração", coisas mais frágeis, a se excetuar os livros até agora escritos sobre Machado de Assis. Algumas das traduções de obras dele para o francês e o italiano, e a pavorosa estátua que, além de outros defeitos de feia, entope a deliciosa fachada do Petit Trianon. E enfim a parte mais audaciosa da exposição, em que os organizadores dela tomam uma atitude exclusivamente crítica, e se reproduz aqui. Aí vêm de qualquer forma evocados os gênios que mais influenciaram a formação técnica e espiritual do nosso gênio literário, Camões, Frei Luís de Sousa, Garrett, Pascal, o Eclesiastes, Daniel [sic] Sterne, além das obras do nosso mestre principal. E, talvez em contradição com alguns desses nomes evocados, vem ainda a frase de Machado de Assis, dizendo que "de todas as coisas humanas, a única que tem o seu fim em si mesma é a arte". Essa arte pela qual ele tudo sacrificou, até o equilíbrio da sua humanidade... 


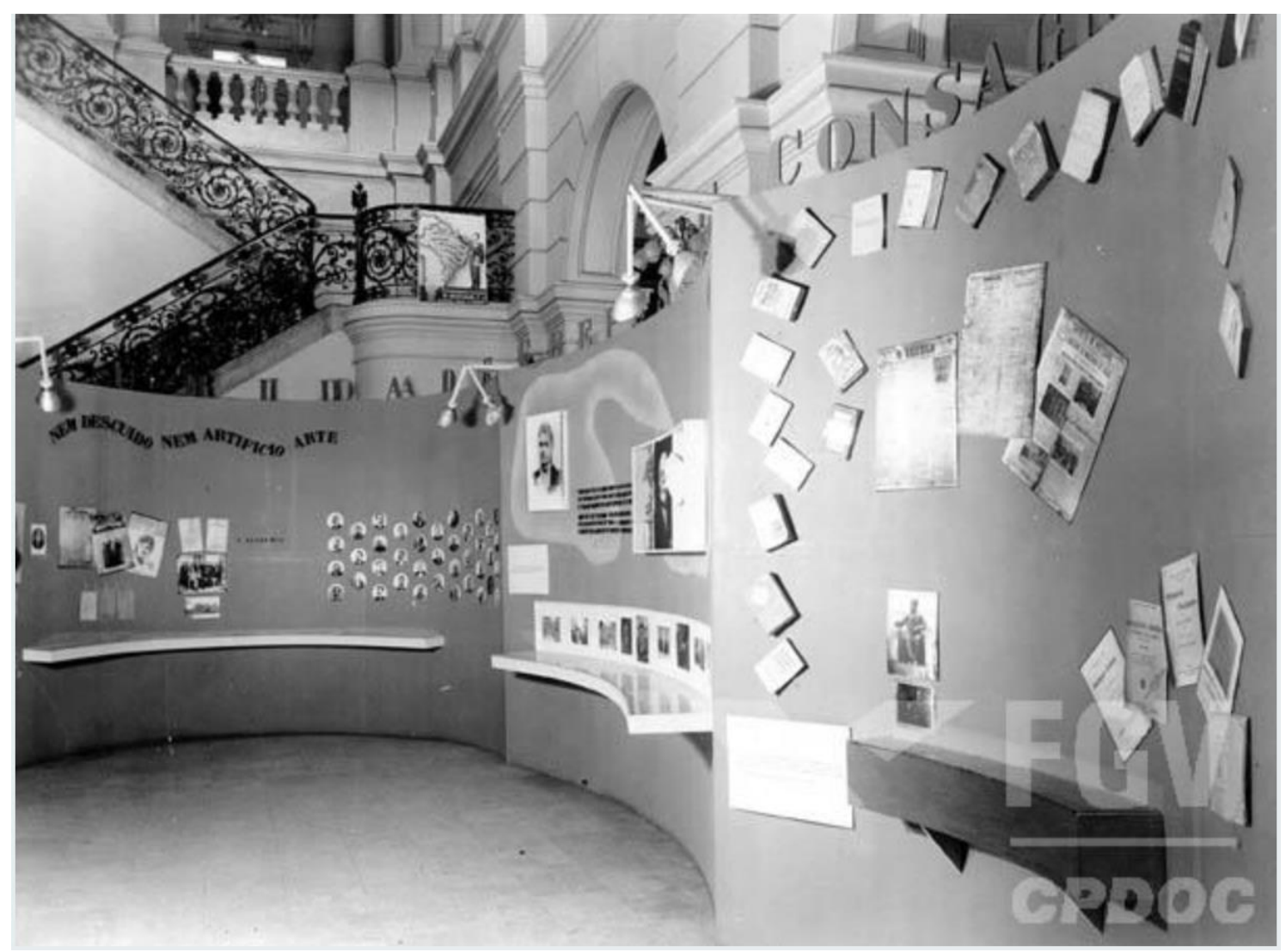

Figura 1: Vista parcial da exposição, no hall da Biblioteca Nacional.

Fonte: Fotografia de Stefan Rosenbauer, acervo CPDOC-FGV, Rio de Janeiro. 


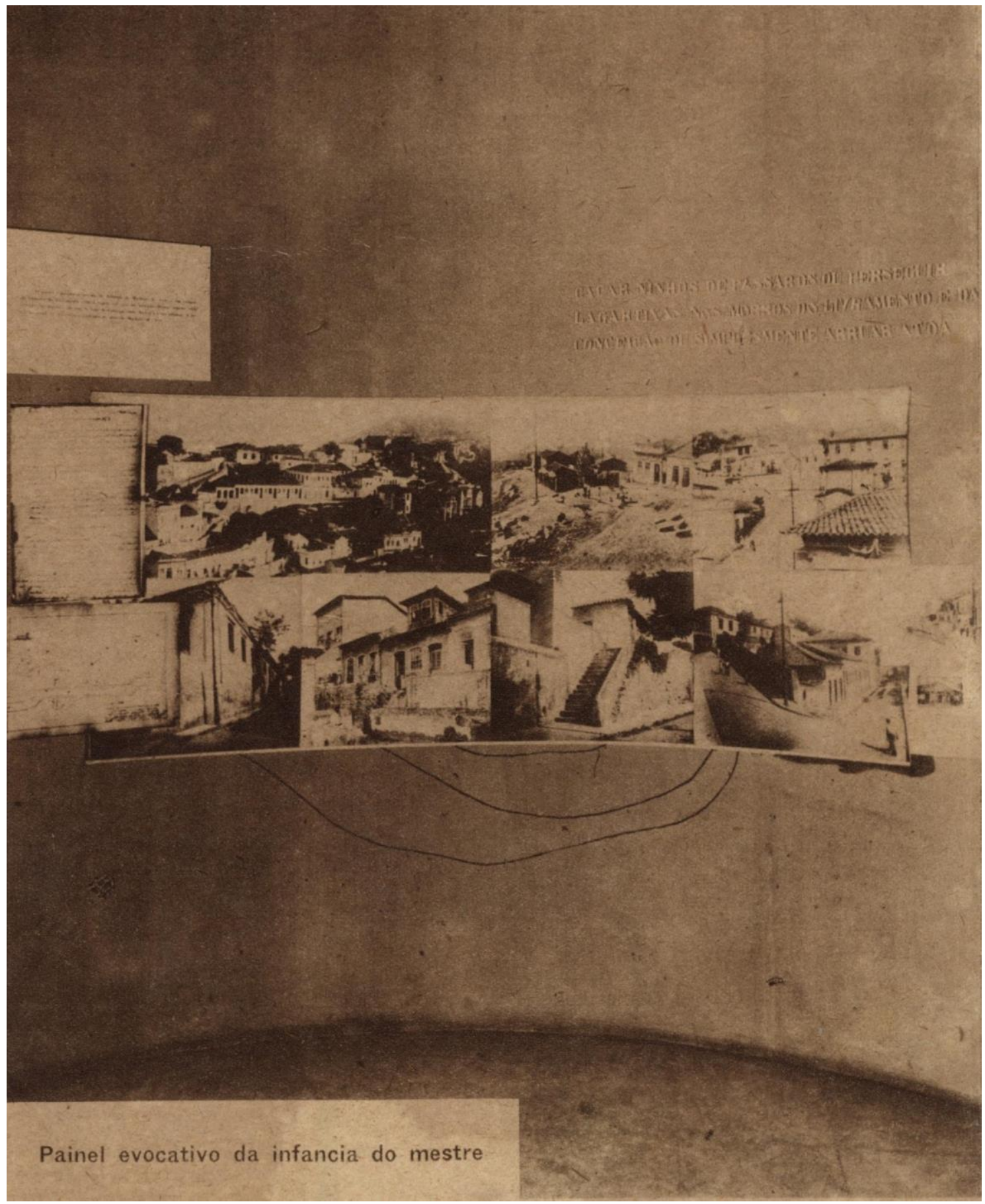

Figura 2: "Painel evocativo da infância do mestre".

Fonte: O Estado de S. Paulo, suplemento, $1^{a}$ quinzena de agosto de 1939. 


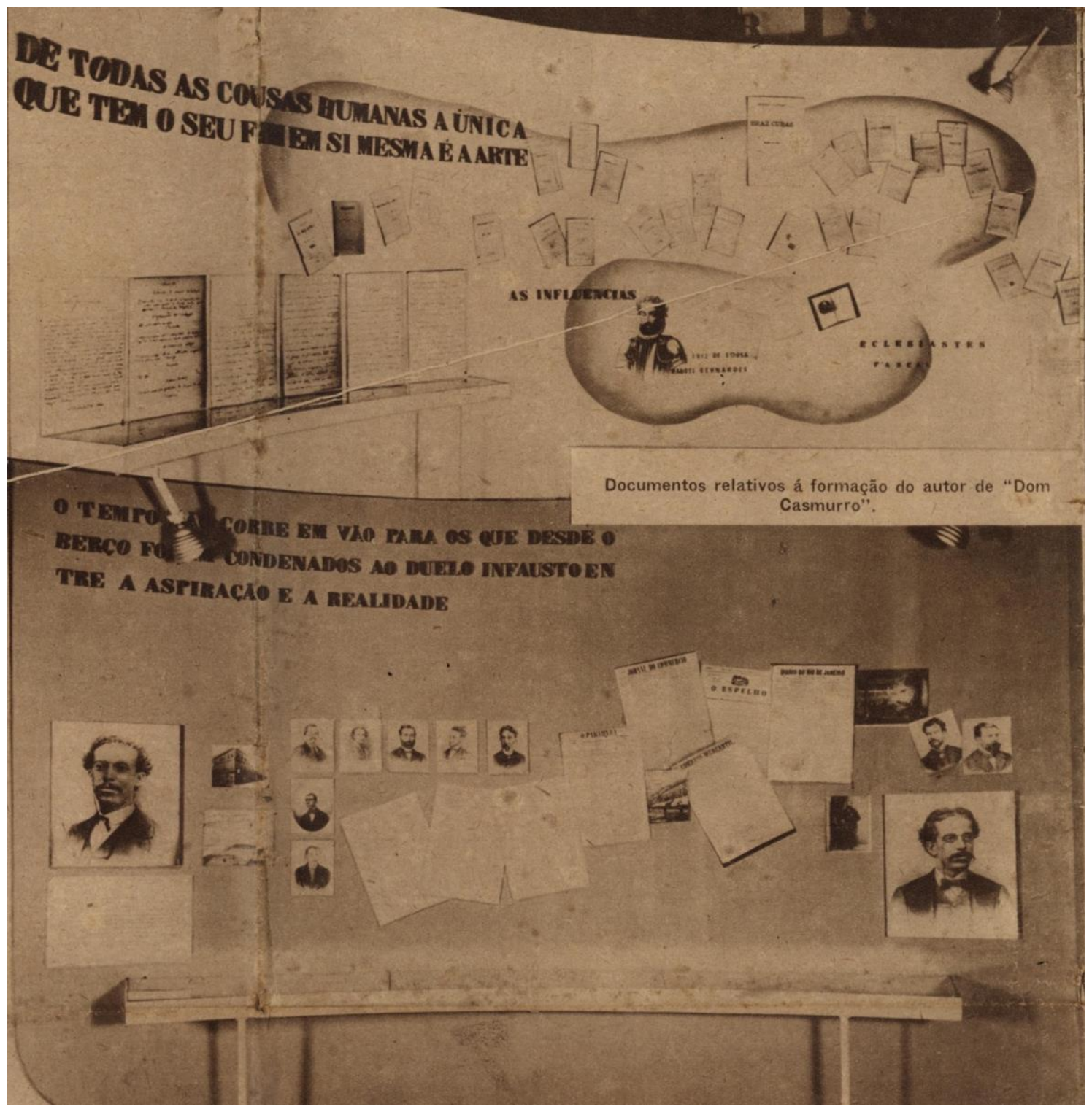

Figura 3: "Documentos relativos à formação do autor de Dom Casmurro" (acima) e "'A obra', último dos painéis que figuram na interessantíssima exposição" (abaixo). Fonte: 0 Estado de S. Paulo, suplemento, $1^{a}$ quinzena de agosto de 1939.

\section{Referências}

ANDRADE, Mário de. O empalhador de passarinho. São Paulo: Martins, 1955. . Aspectos da literatura brasileira. Rio de Janeiro: Editora America, 1943. . Vida literária. Organização de Sonia Sachs. São Paulo: Hucitec; Edusp, 1993.

CASTRO, Moacir Werneck de. Mário de Andrade: exílio no Rio. Rio de Janeiro:

Rocco, 1988. 
GUIMARÃES, Hélio de Seixas; LEBENSZTAYN, Ieda (Orgs.). Escritor por escritor: Machado de Assis segundo seus pares (1908-1939). São Paulo: Imprensa Oficial do Estado de São Paulo, 2019.

MINISTÉRIO DA EDUCAÇÃO E SAÚDE PÚBLICA. Catálogo da Exposição Machado de Assis: centenário do nascimento de Machado de Assis, 1839-1939. Rio de Janeiro: Serviço Gráfico do Ministério da Educação e Saúde, 1939.

MARCELO DIEGO (D. https://orcid.org/0000-0001-8590-5009 